Original Article

\title{
DENTAL CARIES AND FLUORIDE LEVELS IN WATER AND MILK IN 13-15YEAR OLD ADOLESCENT POPULATION IN DAKSHINA KANNADA DISTRICT, INDIA
}

\author{
Mithra N. Hegde', Ashwitha Punja', Ganesh Bhat ${ }^{3} \&$ Uday S. Mahale ${ }^{4}$ \\ ${ }^{1}$ Senior Professor \& HOD, Department of Conservative Dentistry and Endodontics, \\ ${ }^{2}$ Professor, 3 Reader, ${ }^{4}$ Post Graduate Student \\ A.B. Shetty Memorial Institute of Dental Sciences, Deralakatte, Nitte University, Mangalore - 575018 \\ Correspondence \\ Mithra N. Hegde \\ Senior Professor and HOD, Department of Conservative Dentistry and Endodontics \\ A.B. Shetty M emorial Institute of Dental Sciences, Deralakatte, M angalore - 575018 \\ E-mail : drhegdedentist@gmail.com
}

Abstract:

\section{Introduction}

Dental caries is an infectious microbiological disease affecting all age groups. Fluoride slows down the progression of an existing carious lesion thus reducing the incidence of dental caries. World Health Organisation (WHO) recommends 0.5 to $1 \mathrm{ppm}$ fluoride content in community water supply and milk fluo ridation in case of non-feasibility of community water fluoridation. The aim of present study was to determine fluoride levels in water and milk in Dakshina Kannada District and to co-relate them with the DM FT scores in $13-15$ year old adolescent population.

\section{Methodology}

Water samples were collected from six different regions and sources from Dakshina Kannada District. Water samples were tested for fluoride content by ion specific electrode. A school dental survey was conducted to determine different brands of milkconsumed by the children and their DM FT index. M ilksamples were tested for fluoride levels by lon Specific electrode using TSAB-II solution. DM FT scores were correlated with fluo ride level of milk consumed by population. Interobesrver reliability by kappa statistics and association test with one way ANOVA was done.

\section{Results}

The range of fluoride levels in waters samples was 0.01 to $0.17 \mathrm{ppm}$ and that of milk samples was 0.176 to $1.38 \mathrm{ppm}$. There was no much difference in fluoride levels of different milk sources. Hence association between DMFT and milk fluoride levels was not statistically significant $(p=0.2)$.

\section{Conclusion}

Negligible amounts of Fluoride levels were found in water and milk. There is scope to conduct milk or water fluoridation programme in South Kannada District as a caries prevention method.

Keywords: Fluoride, DM FT, Survey, Adolescent

\section{Introduction:}

Dental caries is a major dental disease affecting a large population of the world. It

\begin{tabular}{|c|}
\hline Access this article online \\
\hline Quick Response Code \\
\hline$\square$ \\
\hline
\end{tabular}

causes pain and discomfort thus impairing the quality of life. Also, it imposes a huge financial burden on health service programmes. Fluoride as a cariostatic agent has been long studied and clinically proven as well. Increased use of fluoride as a systemic and topical agent has led to the decline of dental caries ${ }^{1}$.

Recommended fluoride level in community drinking water is $1 \mathrm{ppm}{ }^{2}$.

Fluoride's role in caries prevention is well documented. Fluoride concentration adjustment for caries control first began in 1945-46 in United States and Canada in the drinking water supplying four communities ${ }^{3-6}$. 
Dakshina kannada district has no centralised water supply. Hence community water fluoridation in not feasible, therefore milk fluoridation can be considered. M ilk being an important source of both macro- and micronutrients and a staple in diet for children, it is thought to be an appropriate medium. Fluoride is as easily absorbed from milkasfrom water ${ }^{2}$.

Systemic fluoride affects teeth during the developmental stages. It gets incorporated into the hydroxyapatite crystals forming fluorapatite which is more resistant to acid dissolution. This is a pre-eruptive effect. It also has a local post-eruptive effect as it is a component of saliva?.

Thus the aim of the present study was to determine the fluoride levels in water and milk in Dakshina Kannada district and co-relate it with dental caries in adolescent population.

\section{Materials and Methods:}

Estimation of fluo ride levels in water samples:

Drinking water samples were collected from six different regions and sources from Dakshina Kannada District. Different sources included bore well water, well water, municipal corporation water, drinking water at public mall, drinking water at educational institution.Water samples were tested for fluoride content with help of ion specific electrode (Orion, Beverely, USA).

Estimation of dental caries:

A survey was conducted at Government High School, Babbukatte, Dakshina Kannada District, India to determine:- a. which different sources of milk were consumed and since how long duration b. DM FT index of school children. 201 students between 13-15years age group were selected. Students consuming milk since less than 5 years were excluded. Survey was conducted by two dentists. First forty students were examined by both the dentists to check the inter observer reliability. Written consent was taken prior to survey from the school children's parents for their ward's inclusion in the study. Sample size for main survey was determined after conducting a pilot survey with forty one sample size
Questionnaire form was explained to school students one day before survey. Students were instructed to find out answers for the survey questions.Intraoral examination was done under day light illumination with help of mouth mirror and straight probe.Required protective barriers were used and disinfection protocol was followed. Students, who did not know answer of questions, were contacted next day to acquire the answers.

Fluoride Estimation of Milk Samples:

Observations of school dental survey showed that, milk from following sources were consumed most commonly by students:- Nandini blue, Nandini green, Amul Powdered Milk, Fresh Cow Milk. These milk samples were tested for fluoride levels using lon Specific Electrode (Orion, Beverely, USA)and TSAB-II solution (Sigma Aldrich Company, $M$ issouri, USA)

\section{Statistical Analysis:}

Interobserver reliability was checked using kappa statistics. Association between DMFT scores and fluoride level of milk was determined by one way ANOVA test. Statistical analysis was done using SPSS (Statistical Package for Social Science) version 16.

\section{Results:}

Interobserver reliability test showed kappa value of 0.8 which is excellent agreement with statistical significance.

The range of fluoride levels in waters samples was 0.01 to $0.17 \mathrm{ppm}$ and that of milk samples was 0.176 to $1.38 \mathrm{ppm}$. Table 1 shows the fluoride levels of water samples collected from different areas of Dakshina Kannada District.

15 students were consuming milk since less than last 5 years hence they were excluded. Fluoride levels observed were in range of 0.176 to $1.38 \mathrm{ppm}$ within the milk samples tested. Increase in milk fluoride level showed decrease in DMFT scores except for the fresh cow milk with $0.3 \mathrm{ppm}$ fluoride levels where maximum mean DMFT score was found (Table 2). One way ANOVA showed no significance association between DMFT score and milk fluoride level $(p=0.2)$. 


\section{Discussion:}

The present study has provided an interesting insight into milk, water fluoride levels and caries experience among Dakshina Kannada District in adolescent students. The results will be helpful in motivating the milk or water fluoridation programmes at administrative level to decrease caries incidence from the study areas. These results will also serve as base-line data for the future comparisons.

Fluoride contents of drinking water and different sources of milk in Dakshina Kannada District are below WHO recommended levels. Natural water and milk fluoride levels reflect the overall fluoride availability in an environment ${ }^{2}$. Hence we can conclude that there is scarcity of fluoride in overall environment of Dakshina Kannada District. Amongst all water samples, samples of filtered cooler water from public mall showed minimum fluoride levels while city well water showed maximum fluoride level. It suggests that, may be the filtration must have reduced the fluoride content. Being a coastal area, city well water showed maximum fluoride level. Amongst all milk samples, processed milk showed least fluoride levels. It may suggest Ultra Heat Treatment has reduced the fluoride levels in processed milk.

Systemic fluorides, if administered during period of tooth development i.e. 8 months intra uterine life to 8 years of age, promote the fluorapatite deposition. It results in harder and less soluble enamel surface which is less prone to caries. Also increased levels of fluorides have been found in saliva and gingival crevicular fluid after systemic fluoride consumption $^{2}$. At 13-15 age permanent dentition is recently developed. Effect of systemic fluoridation can be best judged at this age.

Relatively less number of students drinking cow's milk must have resulted high mean value of DM FT. Also, it may suggest that, the caries causative factors viz. more sugar intake, cariogenic dietary habits must have outweighed the milk fluoride levels in students consuming cow's milk. There was no significant difference between the fluoride levels of different milk samples. Hence we could not get statistically significant association between DM FT scores and change in milkfluoride levels.

Previous studies conducted in Dakshina Kannada district have shown dental erosion in $11 \%$ males and $8 \%$ females, abrasion in 18\%males and 13\% females \& attrition in 30\% males and $26 \%$ females ${ }^{8}, 30.9 \%$ prevalence of caries in premolars ${ }^{9}, 26 \%$ prevalence of dentinal hypersensitivity with lower anterior teeth ${ }^{10}$, more than $50 \%$ prevalence of caries in first permanent molar ${ }^{11}$ and $1.2 \%$ prevalence of root caries in overall population ${ }^{12}$. A 5 years retrospective study in Dakshina Kannada District showed 36.06\% prevalence for missing mandibular molar and $30.64 \%$ prevalence of missing maxillary first molar ${ }^{13}$. All these results show that the overall scarcity of fluoride in Dakshina Kannada District has led to increased prevalence of tooth wear and carious lesions.

\section{Conclusion:}

Fluoride content of drinking water in South Kannada District is below WHO recommended levels. Therefore there is necessity of Milk fluoridation of School water fluoridation programme.

\section{Acknowledgment:}

The authors thank NITTE University for funding this study project.

Table 1 : Fluoride levels found in drinking water samples from Dakshina Kannada District

\begin{tabular}{|c|c|}
\hline Water Source & Fluoride as $\mathbf{~ m ~} \mathbf{~ F / ~} \mathbf{~}$ \\
\hline Deralakatte well water & 0.018 \\
\hline Deralakatte bore well & 0.017 \\
\hline Water cooler at M all & 0.010 \\
\hline City Well water & 0.170 \\
\hline Deralakatte water cooler & 0.016 \\
\hline Surathkal water cooler & 0.013 \\
\hline
\end{tabular}


Table 2 : Fluoride Levels found in different sources of Milk consumed by School Children:-

\begin{tabular}{|c|c|c|c|c|c|c|c|}
\hline Milk Source & M ilk Type & \begin{tabular}{|c|} 
Fluoride Level \\
(ppm)
\end{tabular} & $\mathbf{N}$ & $\begin{array}{l}\text { Mean } \\
\text { DMFT }\end{array}$ & $\begin{array}{l}\text { Standard } \\
\text { Deviation }\end{array}$ & $\begin{array}{l}\text { Mean } \\
\text { Square }\end{array}$ & $\begin{array}{l}\text { Significance } \\
\text { (P) }\end{array}$ \\
\hline Nandini Blue & Pasteurized Toned Cow's Milk & 0.176 & 54 & 2.611111 & 2.413927 & \multirow[t]{4}{*}{9.092} & \multirow[t]{4}{*}{0.207} \\
\hline Nandini Green & Homogenized cow's milk & 0.219 & 102 & 2.294118 & 2.390527 & & \\
\hline Fresh Cow Milk & & 0.301 & 21 & 3.380952 & 2.80136 & & \\
\hline Powder Milk & & 1.38 & 7 & 1.571429 & 1.902379 & & \\
\hline
\end{tabular}

N Number of students consuming milk.

\section{References:}

1. Peter S, Fluorides in preventive dentistry. 3rd edn 2006, Arya Publishing House, India

2. WHO (2009) Milk fluoridation for the prevention of dental caries. Geneva: World Health Organization

3. Blaney JR, Tucker WH. The Evanston Dental Caries Study. II. Purpose and mechanism of the study. J Dent Res. 1948;27:279-86.

4. Ast DB, Finn SB, M cCaffrey I. The Newburgh-Kingston Caries Fluorine Study. I. Dental findings after three years of water fluoridation. Am J Public Health. 1950;40:716-24.

5. Dean HT, Arnold FA, Jay P, Knutson JW. Studies on mass control of dental caries through fluoridation of the public water supply. Public Health Rep. 1950;65:1403--8.

6. Hutton WL, Linscott BW, Williams DB. The Brantford fluorine experiment: interim report after five years of water fluoridation. Can J Public Health. 1951;42:81--7.

7. Moynihan PJ. The relationship between diet, nutrition and dental health: an overview and update for the 90s. Nutrition Research Reviews. 1995;8:193-224

8. Hegde MN, Singh SK. Prevalence of Tooth Wear and its Relation to Dietary Habit among General Population. JIDA. 2012;2(12):369-71

9. Hegde M N, Shetty S. Prevalence of Caries in Premolars in the District of South Canara, Karnataka, India. JIDA. 2009;3(2):48-9

10. Hegde M N, Bhalla N. The Prevalence of Dentine Hypersensitivity in Southern India. JIDA. 2009;3(6):625-7

11. Hegde M N, Shija AS. Carious First M olars in South Canara Population An Epidemiological Study. JIDA. 2011;5(11):1132-4

12. Hegde $M N$, Jyothi $M$. Prevalance of root surface caries among population of South Canara District of Karnataka- an Epidemological study. JIDA. 2011;5(5):616-8

13. Hegde M N, Ragavendran N. Prevalance of missing first molar on South Indian population - A retrospective study. IJRD. 2012;1(1):25-9 